\title{
Free Tissue Transfer in Pressure Ulcer Reconstruction: A Systematic Review
}

\author{
Chelsi Robertson, BS ${ }^{1}$ Charles Patterson, MD² Hugo St. Hilaire, MD, DDS, FACS ${ }^{2}$ \\ Frank H. Lau, MD, FACS² \\ ${ }^{1}$ School of Medicine, Louisiana State University, New Orleans, \\ Louisiana \\ 2 Department of Surgery, Section of Plastic and Reconstructive \\ Surgery, Louisiana State University Health Sciences Center; New \\ Address for correspondence Frank H. Lau, MD, FACS, LSUHSC, \\ Department of Surgery, Section of Plastic and Reconstructive Surgery, \\ 1542 Tulane Avenue, Room 734, New Orleans, LA 70112 \\ (e-mail: flau@lsuhsc.edu).
} Orleans, Louisiana

J Reconstr Microsurg Open 2021;6:e35-e39.

\begin{abstract}
Keywords

- pressure ulcers

- pressure sores

- free flaps

- free tissue transfer

- recurrence

Background Pressure ulcers (PUs) affect 2.5 million people in the United States annually and incur health-care costs of 11 billion dollars annually. Stage III/IV PU often require local flap reconstruction. Unfortunately, PU recurrence is common following reconstruction; recurrence rates as high as $82 \%$ have been reported. When local flap options are inadequate, free tissue transfer may be indicated but the indications have yet to be delineated. To develop evidence-based guidelines for the use of free flaps in PU reconstruction, we performed a systematic review.

Methods A systematic review of the available English-language, peer-reviewed literature was conducted using PubMed/MEDLINE, Google Scholar, Scopus, EMBASE, and the Cochrane Database of Systematic Reviews. Articles were manually reviewed for relevance.

Results Out of 272 articles identified, 10 articles were included in the final analysis. Overall, this systematic review suggests that free-flap PU reconstruction yields fewer recurrences compared with local flaps (0-20 vs. 13-82\%). Further, several types of free flaps for PU reconstruction were identified in this review, along with their indications. Conclusion Free tissue transfer should be considered for recurrent PU. We offer specific recommendations for their use in PU reconstruction.
\end{abstract}

Pressure ulcers (PUs) affect 2.5 million people in the United States annually and incur health care costs of 11 billion dollars per year. ${ }^{1}$ PU results from unrelieved pressure on soft tissue over a bony prominence. ${ }^{2}$ The resulting wound may be exacerbated by factors that inhibit wound healing, including infection, inflammation, and edema. Approximately $70 \%$ of PUs involve the sacrum, ischial tuberosity, or greater trochanter, while 15 to $25 \%$ affect the lower extremities. $^{3}$

received

October 19, 2020

accepted

February 15, 2021
DOI https://doi.org/ 10.1055/s-0041-1729640. ISSN 2377-0813.
Although PU management is well defined, there remains significant room for improvement. Stage-I and -II PUs can be managed conservatively with local wound care and pressure offloading. Stage-III and -IV PUs require surgical reconstruction because healing by secondary intention is excessively prolonged or stalled. ${ }^{4,5}$ For these ulcers, the reconstructive workhorses are locoregional flaps. ${ }^{2}$ However, 1 -year recurrence rates as high as $82 \%$ (range: $13-82 \%$ ) have been reported. ${ }^{1,6-13}$

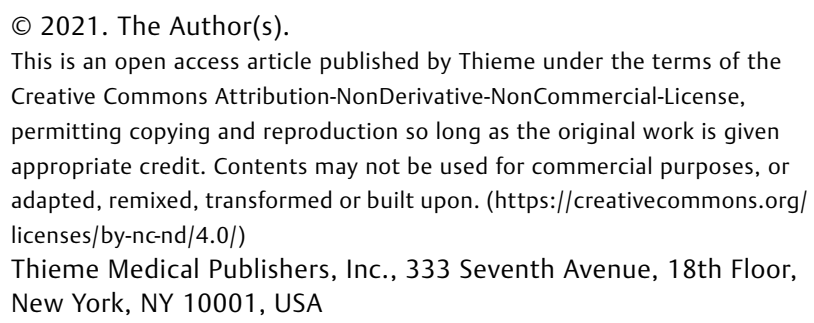


Because of these high recurrence rates and approximately $25 \%$ of PU patients develop additional $\mathrm{PU},{ }^{14,15}$ local flap options can be depleted. In these patients, free flap reconstruction may be required. On preliminary review of the literature, no evidence-based guidelines regarding the use of free flaps in PU reconstruction were identified. Thus, the aims of this study were to perform a systematic review and develop evidence-based guidelines for the use of free flaps in PU reconstruction.

\section{Methods}

\section{Literature Search}

A literature search of available English-language, peerreviewed literature with the help of a professional librarian was conducted. The search was performed in five electronic databases over the period of 1980 to 2019 as follows: (1) PubMed/MEDLINE, (2) Google Scholar, (3) Scopus, (4) EMBASE, and (5) the Cochrane Database of Systematic Reviews. The key words used were a combination of the following terms: "free flap," "free tissue transfer," "pressure ulcer," "pressure sore," “decubitus ulcer," “ischial ulcer," "sacral ulcer," and "trochanteric ulcer." Articles were then manually reviewed for relevance.

\section{Article Eligibility}

Title and abstract of all retrieved records were independently screened for eligibility by two reviewers (C.R. and F.H.L.). To be included, the article had to meet the following inclusion criteria: (1) examined pressure ulcers in the ischium, sacrum, and/or trochanteric regions only, and (2) examined free flaps for pressure ulcer reconstruction. Articles were excluded if: (1) there was no focus on pressure ulcers and surgical intervention, or (2) there was a focus on a specific subpopulation.

\section{Data Extraction}

The following data were extracted from each article and used for descriptive comparisons: author, year, study design, sample size, ulcer location, type of flap, type of recipient vessel, recurrence rate, follow-up period, and study results.

\section{Results}

\section{Systematic Literature Review}

Our initial literature search identified 272 citations (-Fig. 1). After eliminating duplicate articles and screening titles, abstracts, and full texts, 10 articles were included for final analysis (-Table 1). The level of evidence (LOE) was low, eight were case reports (LOE V) and one was a retrospective case series (LOE IV). The highest quality study was a prospective case series (LOE IV) involving 11 spinal cord injury patients with stage-III or -IV ischial PUs who underwent reconstruction with free partial latissimus dorsi myocutaneous flaps. ${ }^{16}$ Overall, the prospective case series and $100 \%$ of the case reports supported free tissue transfer as an effective reconstructive option for wound closure when local flaps are inadequate, depleted, or have failed.

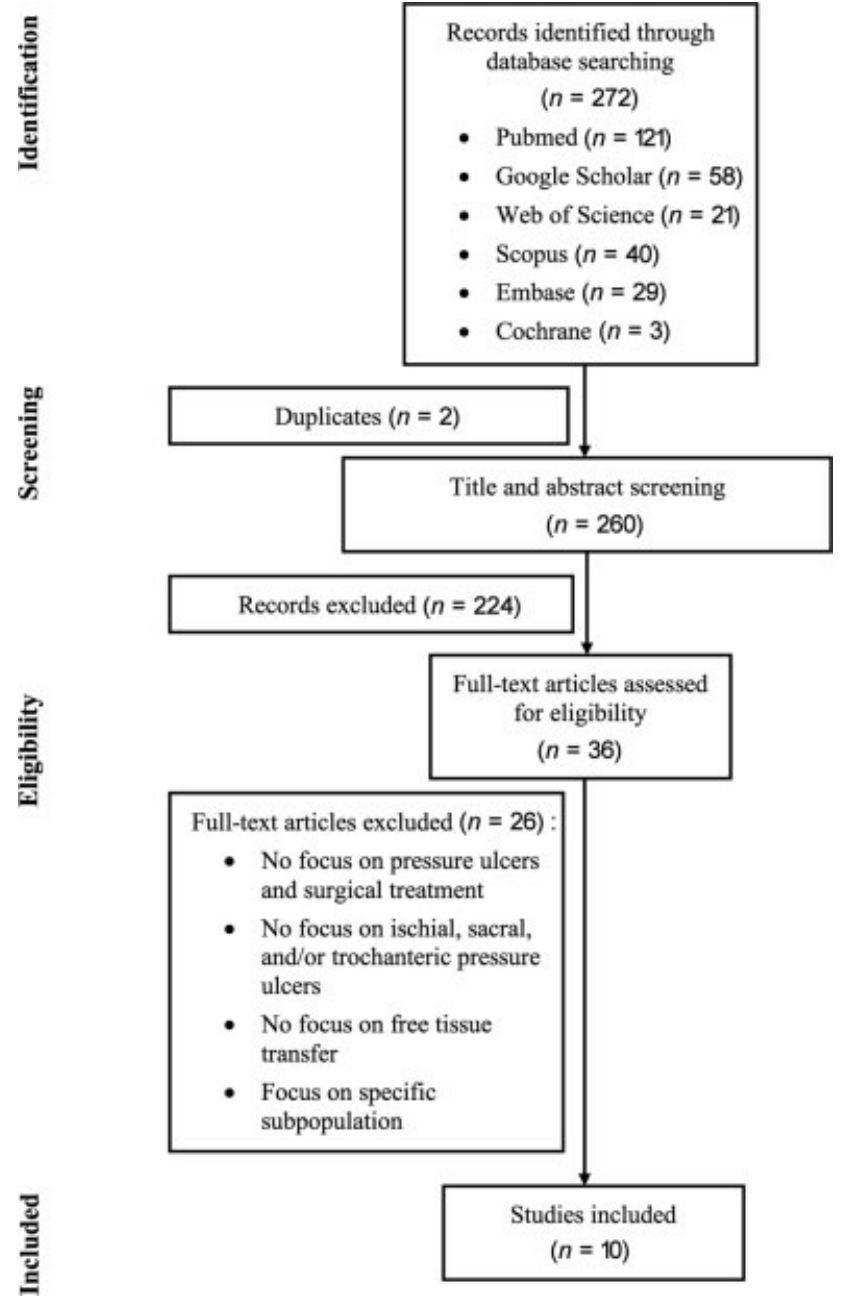

Fig. 1 Schematic of systematic literature review. Flow chart detailing the results of the screening process and final article inclusion for this systematic review of the literature.

\section{Discussion}

Local flaps have been the mainstay of PU reconstruction since the 1970s, and PU recurrence rates have not significantly improved over the years. ${ }^{9}$ Overall, this systematic review suggests that free flap PU reconstruction yields fewer recurrences compared with local flaps (0-20 vs. 13-82\%). Moreover, our review identified several types of free flaps that have been used for pressure ulcer reconstruction along with their indications.

Free flaps that have been used in PU reconstruction include the latissimus dorsi myocutaneous flap, combined latissimus dorsi and serratus anterior muscle flap, and medial gastrocnemius myocutaneous flap. For patients with amputated or nonfunction limbs, the lower extremity is an excellent, low-morbidity donor site. ${ }^{17,18}$ The inferior and superior gluteal vessels are the first choice recipient vessels; the deep femoral and inferior epigastric vessels are suitable recipient vessels, as well.

Flap selection is highly dependent on wound size and potential morbidity of muscle transfer. The latissimus dorsi myocutaneous flap should be selected when a large amount 
Free Tissue Transfer in Pressure Ulcer Reconstruction Robertson et al. e37

\begin{tabular}{|c|c|c|c|c|c|c|c|c|c|c|}
\hline 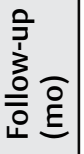 & $\sim$ & $\begin{array}{l}\stackrel{9}{1} \\
\stackrel{1}{\sim}\end{array}$ & $m$ & $\begin{array}{l}0 \\
m\end{array}$ & $\begin{array}{l}0 \\
\infty \\
1 \\
1 \\
\end{array}$ & $\stackrel{\infty}{-}$ & $\begin{array}{l}\infty \\
1 \\
\sim\end{array}$ & 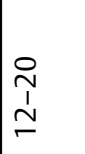 & $\begin{array}{l}\frac{1}{7} \\
\frac{1}{1} \\
\infty \\
-\end{array}$ & $\begin{array}{l}\stackrel{m}{+} \\
\stackrel{1}{\sim} \\
\sim\end{array}$ \\
\hline 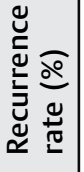 & 0 & 0 & 0 & 0 & 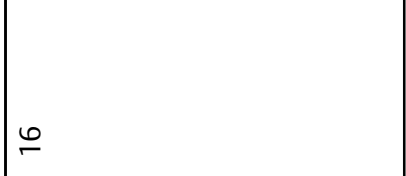 & 0 & 0 & 0 & 0 & $\stackrel{\curvearrowright}{\sim}$ \\
\hline 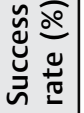 & ○ & $\stackrel{8}{\circ}$ & ○ & ○ & $\infty$ & 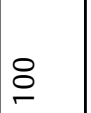 & ○ & 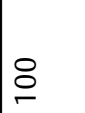 & ○ & $\infty$ \\
\hline 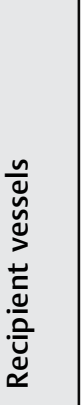 & 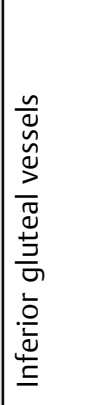 & 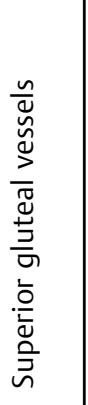 & 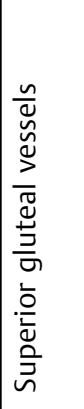 & 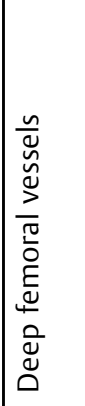 & 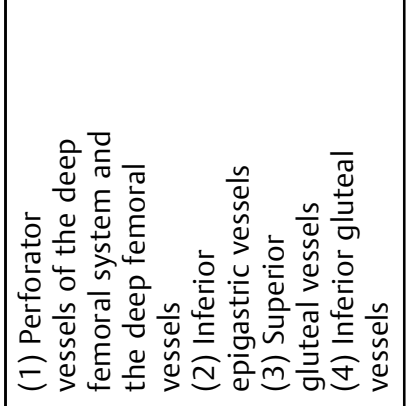 & 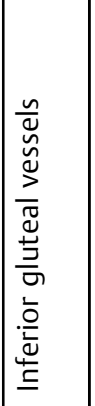 & 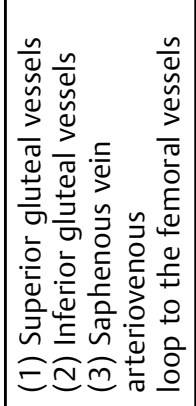 & 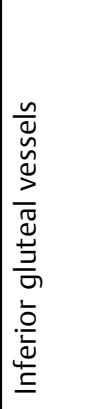 & 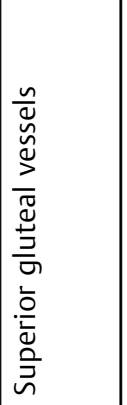 & 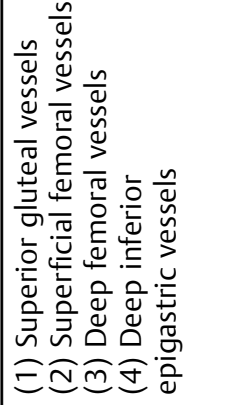 \\
\hline 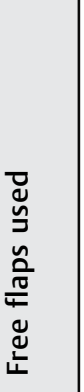 & 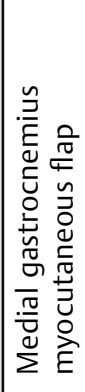 & 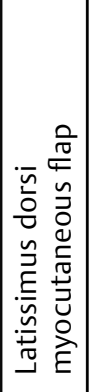 & 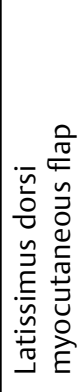 & 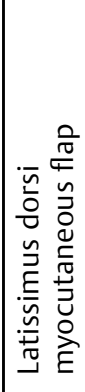 & 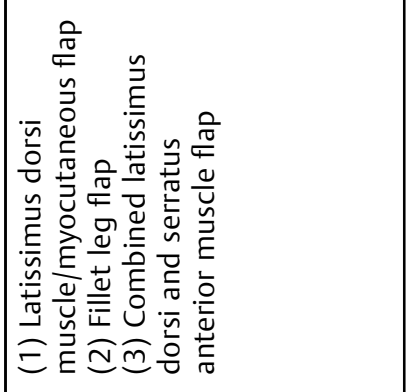 & 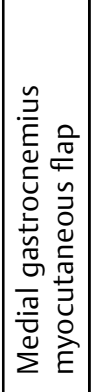 & 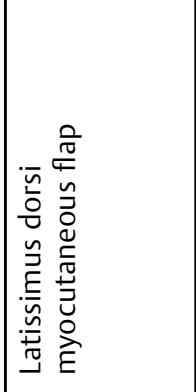 & 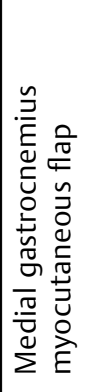 & 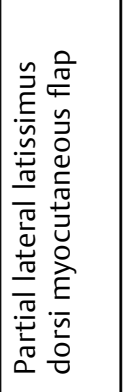 & 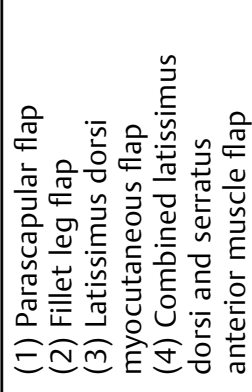 \\
\hline $\begin{array}{l}.0 \\
\stackrel{0}{0} \\
\stackrel{0}{0}\end{array}$ & 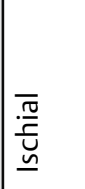 & 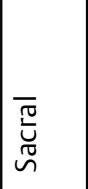 & $\begin{array}{l}\bar{\pi} \\
\stackrel{\widetilde{U}}{\pi} \\
\tilde{n}\end{array}$ & 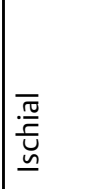 & 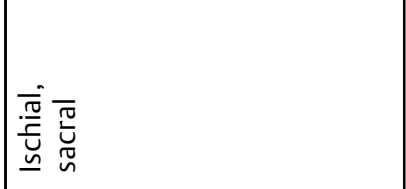 & 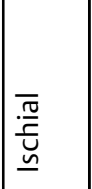 & 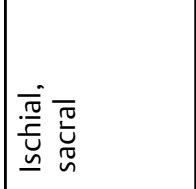 & 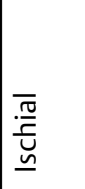 & 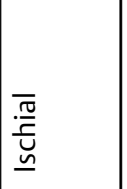 & 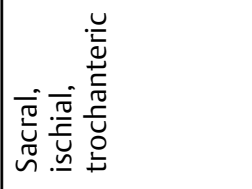 \\
\hline 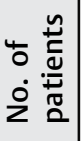 & - & in & - & - & 6 & - & $m$ & $\sim$ & $\mp$ & 6 \\
\hline 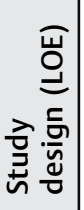 & 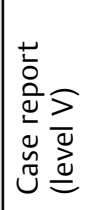 & 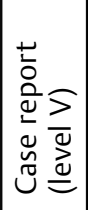 & 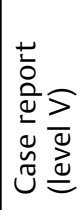 & 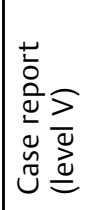 & 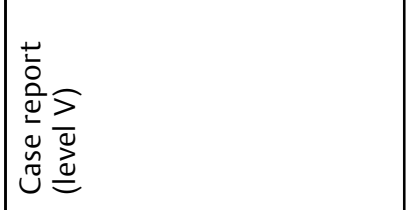 & 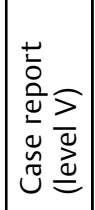 & 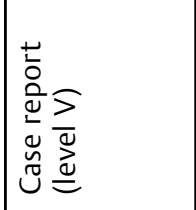 & 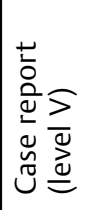 & 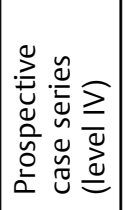 & 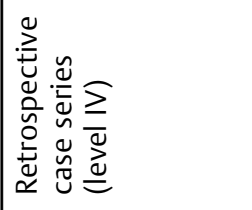 \\
\hline 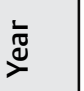 & 늠 & 吕 & $\frac{0}{\stackrel{\sim}{\sim}}$ & 文 & 方 & 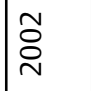 & 兑 & 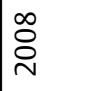 & $\stackrel{\sim}{\stackrel{N}{N}}$ & 文 \\
\hline 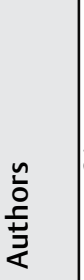 & $\mid \begin{array}{l}\frac{\bar{v}}{\breve{y}} \\
\frac{\underline{0}}{\bar{T}} \\
\frac{\pi}{I}\end{array}$ & 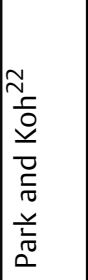 & 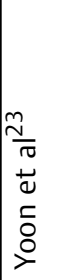 & 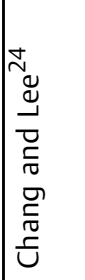 & 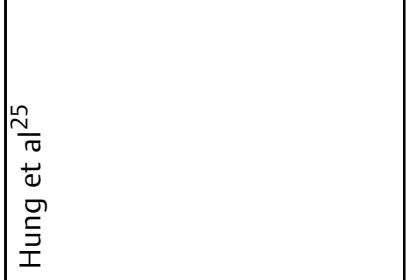 & 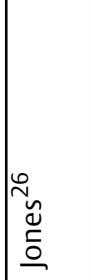 & 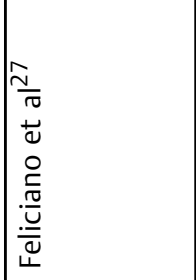 & 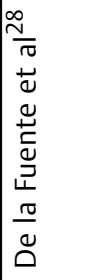 & 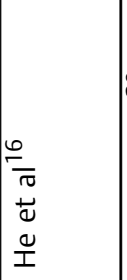 & 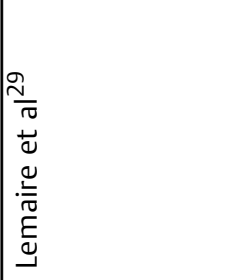 \\
\hline
\end{tabular}


Table 2 Four evidence-based guidelines for the use of free flaps in pressure ulcer reconstruction

\begin{tabular}{|l|l|}
\hline 1. & $\begin{array}{l}\text { Adjacent tissue is compromised leaving few appropriate local flaps for coverage. Reasons for compromise include } \\
\text { prior surgeries, radiation therapy, refractory infection, and diminished vascularity }\end{array}$ \\
\hline 2. & Free flaps should be used if local flap options have been exhausted \\
\hline 3. & $\begin{array}{l}\text { Free flaps should be considered for patients prone or more susceptible to recurrent pressure ulcer. This vulnerable } \\
\text { population includes patients with limited mobility and altered sensorium such as paraplegics or patients with spinal } \\
\text { cord injuries }\end{array}$ \\
\hline 4. & $\begin{array}{l}\text { Free flaps can be used in conjunction with fasciocutaneous or myocutaneous flaps to completely fill ulcer cavities too } \\
\text { large for local flap coverage alone }\end{array}$ \\
\hline
\end{tabular}

of well-vascularized tissue is needed for wound coverage. However, this flap may be contraindicated in paraplegic patients that rely on upper body strength for mobility and truncal support. The fillet leg flap provides a substantial amount of soft tissue for adequate wound coverage and filling of the ulcer cavity but should only be selected for patients with nonfunctional limbs due to donor site disfigurement. Lastly, the medial gastrocnemius myocutaneous flap offers adequate volume replacement, sufficient skin coverage, and low donor site morbidity; it can be useful for paraplegic patients that need to preserve upper body musculature for mobility.

Our review found that the latissimus dorsi myocutaneous flap was the most commonly used free flap for sacral ulcers, while the most commonly used free flaps for ischial ulcers were both latissimus dorsi myocutaneous flap and the medial gastrocnemius flap. Although only one trochanteric PU case requiring free tissue transfer was identified in our systematic review, the latissimus dorsi myocutaneous flap provided excellent coverage.

When selecting recipient vessels, the gluteal vessels are most useful for ischial and sacral ulcers. The inferior gluteal vessels have an advantage over the superior gluteal vessels for ischial ulcers in particular due to its closer proximity to the ischium. The inferior epigastric vessels are best suited for trochanteric ulcers, as these vessels are convenient and a great match when the thoracodorsal vessels are used.

Consideration of free flap PU reconstruction should be based on the state of the local tissue, size of the ulcer, and risk of recurrence. Independent risk factors for PU recurrence include age, male sex, altered sensorium, moisture, immobility, malnutrition, and friction injury. ${ }^{19}$ The populations most at risk for developing PU are the elderly, acutely ill patients, and those with impaired mobility or sensation. In the paraplegic patient, ischial PU develop due to prolonged pressure on the ischial tuberosity. ${ }^{20} \mathrm{PU}$ recurrence is a major problem for these patients, even when closure is performed under minimal tension.

Free flaps are useful for recurrent and chronic PU when local flap options are limited due to local tissue fibrosis or when local flap options have been exhausted. In circumstances of local tissue compromise and infection, free flaps incorporating muscle can eliminate dead space and enhance infection control by improving vascularity of the wound and surrounding tissue. ${ }^{16}$ Free flaps also provide adequate wound coverage when local flaps are not large enough or when patients lack ample local subcutaneous tissue.

\section{Conclusion and Recommendations}

Overall, we believe free tissue transfer should be considered for recurrent PU and we offer specific indications for their use in PU reconstruction (- Table 2 ).

\section{Financial Disclosure Statement}

No funding was received for this article.

Conflict of Interest

None declared.

\section{References}

1 Chiu Y-J, Liao W-C, Wang T-H, et al. A retrospective study: Multivariate logistic regression analysis of the outcomes after pressure sores reconstruction with fasciocutaneous, myocutaneous, and perforator flaps. J Plast Reconstr Aesthet Surg 2017;70(08):1038-1043

2 Bauer JD, Mancoll JS, Phillips LG. Pressure Sores. In: Thorne CHM, Beasley RW, Sherrell J, Bartlett Sp, Gurtner G, eds. Grabb and Smith's Plastic Surgery. 6th ed. Philadelphia, PA: Lippincott Williams \& Wilkins; 2006

3 Mervis JS, Phillips TJ. Pressure ulcers: Pathophysiology, epidemiology, risk factors, and presentation. J Am Acad Dermatol 2019;81 (04):881-890

4 Bauer J, Phillips LG. MOC-PSSM CME article: Pressure sores. Plast Reconstr Surg 2008;121(1, suppl):1-10

5 Bass MJ, Phillips LG. Pressure sores. Current Problems in Surgery 2007;42(02):101-143. Doi: 10.1067/j.cpsurg.2006.12.007

6 Keys KA, Daniali LN, Warner KJ, Mathes DW. Multivariate predictors of failure after flap coverage of pressure ulcers. Plast Reconstr Surg 2010;125(06):1725-1734

7 Thiessen FE, Andrades P, Blondeel PN, et al. Flap surgery for pressure sores: should the underlying muscle be transferred or not? J Plast Reconstr Aesthet Surg 2011;64(01):84-90

8 Disa JJMD, Carlton JMMD, Goldberg NHMD. Efficacy of operative cure in pressure sore patients. Plast Reconstr Surg 1992;89(02): 272-278

9 Tavakoli K, Rutkowski S, Cope C, et al. Recurrence rates of ischial sores in para- and tetraplegics treated with hamstring flaps: an 8year study. Br J Plast Surg 1999;52(06):476-479

10 Relander M, Palmer B. Recurrence of surgically treated pressure sores. Scand J Plast Reconstr Surg Hand Surg 1988;22(01):89-92

11 Larson DL, Hudak KA, Waring WP, Orr MR, Simonelic K. Protocol management of late-stage pressure ulcers: a 5-year retrospective study of 101 consecutive patients with 179 ulcers. Plast Reconstr Surg 2012;129(04):897-904 
12 Evans GRD, Dufresne CR, Manson PN. Surgical correction of pressure ulcers in an urban center: is it efficacious? Adv Wound Care 1994;7(01):40-46

13 Kierney PC, Cardenas DD, Engrav LH, Grant JH, Rand RP. Limbsalvage in reconstruction of recalcitrant pressure sores using the inferiorly based rectus abdominis myocutaneous flap. Plast Reconstr Surg 1998;102(01):111-116

14 Kierney PC, Engrav LH, Isik FF, Esselman PC, Cardenas DD, Rand RP. Results of 268 pressure sores in 158 patients managed jointly by plastic surgery and rehabilitation medicine. Plast Reconstr Surg 1998;102(03):765-772

15 Schryvers OI, Stranc MF, Nance PW. Surgical treatment of pressure ulcers: 20-year experience. Arch Phys Med Rehabil 2000;81 (12):1556-1562

16 He J, Xu H, Wang T, Ma S, Dong J. Treatment of complex ischial pressure sores with free partial lateral latissimus dorsi musculocutaneous flaps in paraplegic patients. J Plast Reconstr Aesthet Surg 2012;65(05):634-639

17 Küntscher MVMD, Erdmann D, Homann H-HMD, Steinau H-UMD, Levin SLMD, Germann G. The concept of fillet flaps: classification, indications, and analysis of their clinical value. Plast Reconstr Surg 2001;108(04):885-896

18 Roulet S, Le Nail L-R, Vaz G, et al. Free fillet lower leg flap for coverage after hemipelvectomy or hip disarticulation. Orthop Traumatol Surg Res 2019;105(01):47-54

19 Kwon R, Rendon JL, Janis JE. Pressure sores. In: Song DH, Neligan PC, Liu DZ, eds. Plastic Surgery: Lower Extremity, Trunk, and Burns. Vol. 4;4th ed. London, United Kingdom: Elsevier; 2018: $350-380$
20 Kuo P-J, Chew K-Y, Kuo Y-R, Lin P-Y. Comparison of outcomes of pressure sore reconstructions among perforator flaps, perforatorbased rotation fasciocutaneous flaps, and musculocutaneous flaps. Microsurgery 2014;34(07):547-553

21 Hallock GG. Closure of an ischial pressure sore using a free gastrocnemius musculocutaneous flap with a long venous pedicle. Br J Plast Surg 1995;48(07):504-506

22 Park S, Koh KS. Superior gluteal vessel as recipient for free flap reconstruction of lumbosacral defect. Plast Reconstr Surg 1998; 101(07):1842-1849

23 Yoon S, Jeong E, Lázaro HA. Multidisciplinary approach to an extended pressure sore at the lumbosacral area. Arch Plast Surg 2016;43(06):586-589

24 Chang L-R, Lee J-W. Free flap coverage of gluteal defect using posteriorly translocated deep femoral vessels as recipient. Microsurgery 2008;28(03):157-159

25 Hung SJ, Chen HC, Wei FC. Free flaps for reconstruction of the lower back and sacral area. Microsurgery 2000;20(02):72-76

26 Jones JW. Reinnervated medial gastrocnemius free flap for closure of a recurrent ischial pressure sore: case report. J Reconstr Microsurg 2002;18(05):397-400

27 Feliciano B, Paige KT, Beshlian KM. Latissimus dorsi free flaps for complex ischiosacral defects. Am J Surg 2007;193(05): $648-650$

28 de la Fuente TP, González I, Calderón-Muñoz F. The role of medial gastrocnemius free flap in coverage of ischial pressure sore in paraplegic patients. Int J Surg 2008;6(06):e72-e76

29 Lemaire V, Boulanger K, Heymans O. Free flaps for pressure sore coverage. Ann Plast Surg 2008;60(06):631-634 